\title{
COBERTURAS SEDIMENTARES E VULCANO-SEDIMENTARES PRE-CAMBRIANAS DAS FOLHAS: SB. 20 PURUS, SC. 20 PORTO VELHO E SC. 21 JURUENA (PLATAFORMA AMAZÔNICA)
}

\author{
R. M. G. DE MONTALVÃO \\ G. H. SILVA \\ P. E. L. BEZERRA \\ O. N. DOS SANTOS PIMENTA \\ MME - DNPM - PROJETO RADAMBRASIL (CEPED)
}

\begin{abstract}
This paper will consider only some of the Precambriam cover units of the Amazonian Platform: those which appear in the SB.20 Purus, SC.20 Porto Velho and SC. 21 Juruena Sheets, and which present the greatest problems of nomenclature and stratigraphic position. The Beneficente Group comprises a sedimentary sequence wich is disturbed in the present region and rests with parallel and erosional discordance on the volcanic-plutonic Uatumã Group. $\mathrm{Rb} / \mathrm{Sr}$ isochron ages $1589+36$ m.y. and $! 548+28$ m.y. are recorded for the volcanism and the granites (Teles Pires Granite) respectively. The sedimentary unit is intruded by a syenitic lithology with a conventional $\mathrm{Rb} / \mathrm{Sr}$ age of $1349+40$ m.y. and phonolitic rocks with a conventional $\mathrm{Rb} / \mathrm{Sr}$ age of 1160 + .36 m.y. The Mutum-Paraná Formation outcropping in the central northwest part of the SC. 20 Porto Velho Sheet is correlated with a belt in the south east part of the same sheet

and in the southwest of the SC.21 Juruena Sheet. This unit was affected by the intrusive granite of Serra da Providência, with conventional $\mathrm{Rb} / \mathrm{Sr}$ age from 1400 to 1200 m.y. The Caiabis Group which follows is composed of conglomerates and arkoses, with intercalations of basalt in more restricted areas, as well as occurrences of andesite and rhyolite probably associated with the sediments. This volcanic-sedimentary sequence shows a K/Ar age for the basalts of $1400-1200$ m.y. The Guajará-Mirim Group forms a sequence of volcanic-sedimentary lithologies of similar type to the Caiabis Group, with a K/Ar age between 1100 and 1000 m.y. The Dardanelos and Prainha Formations will be discussed in this paper as probable correlates of the Caiabis Group. In general these cover units probably constitute stages of transition and stabilization of the Amazonian Platform, as well as post-platform reactivations.
\end{abstract}

\section{LOCALIZAÇĀO DA AREA}

A área em apreço constitui uma porção da região amazônica, ocupando terras dos estados do Amazonas, Pará e Mato Grosso e Territorio Federal de Rondônia. Pelo encarte cartografico internacional corresponde às Folhas SB.20 Purus, Sc.20 Porto Velho e SC.21 Juruena. A primeira com coordenadas geograficas que correspondem aos paralelos $4^{\circ} \mathrm{OO}$ 'S $8^{\circ} 00^{\prime}$ 'S e meridianos $60^{\circ} 00^{\prime}$ e $66^{\circ} 00^{\prime} \mathrm{W}$.Gr., a segunda de coordenadas geográficas com paralelos $8^{\circ} 00^{\prime} \mathrm{S}$ e $12^{\circ} 00^{\prime} \mathrm{S}$ e meridianos $60^{\circ} 00^{\prime}$ e $66^{\circ} 00^{\circ} \mathrm{W}$. Gr., e a terceira com coordenadas correspondentes aos paralelos $8^{\circ} 00^{\prime} \mathrm{S}$ e $12^{\circ} 00^{\prime} \mathrm{S}$ e meridinos de $54^{\circ} 00^{\prime}$ e $60^{\circ} 00^{\prime}$ W.Gr. 


\section{OBJETIVOS}

O principal objetivo é mostrar de maneira ainda preliminar um estudo sobre as coberturas sedimentares e vulcano-sedimentares pré-cambrianas que assomam na area em pauta.

\section{ESTRATIGRAFIA}

As sequências sedimentares e vulcano-sedimentares aqui expostas pertencem ao estágio terminal (?) ou transição e/ou de reativaçðes da Plataforma Amazônica, na área em questão.

Com o esmorecimento do vulcano-plutonismo (Grupo Uatuma) os movimentos verticais continuaram com formaçðes, de bacias controladas por falhas. Entre as depressōes estruturais formou-se o aulacógeno (Almeida, 1974) ou Graben do Cachimbo (Silva et alii, no prelo) seguida de uma espessa sedimentação de mar raso com transição para o continente. A sedimentação é constituída predominantemente de arenitos com menor contribuição de conglomerados, folhelhos, siltitos, margas, calcários, chert e fosfato. Essa sequência denominada de Grupo Beneficente (Almeida e Nogueira Filho, 1959) repousa em discordância erosiva e paralela sobre o grupo Uatumă.

Na extremidade sudoeste da Folha SC.21 Juruena e na extremidade sudeste e nordeste da Folha SC. 20 Porto Velho, ocorrem arenitos feldspáticos, arcóseos, formação ferrífera, metassiltitos, quartzitos e filonitos com (intensa movimentação vertical de blocos) metamorfísmo local, condicionados principalmente a zonas de falha, denominados de Grupo Beneficente por Leal et alii (1978) e Silva et alii, (op. cit.), e correlacionados por Pinto Filho et alii (1976) à Formação $\mathrm{Mu}$ tum-Paraná (Lobato et alii, 1966). Neste trabalho admite-se tal sequência possivelmente sincrônica ou anterior ao Grupo Beneficente, mas com características litoestratigráficas diferentes, daí concordar-se com a proposta de Pinto Filho et alii (op. cit.), até que novos conhecimentos venham elucidar o problemà. No domínio do graben ou aulacógeno do Cachimbo e fora deste, segue-se a sedimentação com características continentais, composta de arenitos tipo red beds, conglomerados e siltitos repousando ora sobre o Grupo Beneficente, ora soore as valcânicas, constituindo a Formaçăo Prainha (Almeida e Nogueira Filho, op. cit.), admitida aqui como sendo de idade pré-cambriana superior. E provável que concomitante com a deposição da Formação Prainha, formava-se o graben dos Caiabis de Silva et alii (op. cit.), com preenchimento de arenitos, arcóseos e basaltos, formando uma sequência vulcano-sedimentar denominada de Grupo Caiabis (Silva et alii, op. cit) e que nos domínios da Cachoeira de Dardanelos, no rio Aripuanã, sem a presença de vulcânicas, foi denominada de Formação Dardanelos por Almeida e Nogueira Filho (op. cit.). O Grupo Caiabis apresenta idades $\mathrm{K} / \mathrm{Ar}$ de $1.400 \mathrm{~m} . \mathrm{a} .-1.200 \mathrm{~m}$.a. Acredita-se ainda na correlação dessas unidades litoestratigráficas com a Formação Prainha, baseados principalmente nas características fisicas dos arenitos e estruturais, das litologias. Na Folha SC.20 Porto Velho a exemplo das Folhas SC.21 Juruena e SB.20 Purus, a tectônica controlada por forças verticais é responsável também pela formação de grabens, seguidos por espesso pacote vulcano-sedimentar denominado de Grupo Guajará-Mirim (Leal et alii, op. cit.). O magmatismo básico com idade $\mathrm{K} / \mathrm{Ar}$ $1.100 \mathrm{~m}$.a. $-1.000 \mathrm{~m}$.a. corresponde a um evento mais tardio que o vulcanismo básico do Grupo Caiabis. Acredita-se na edificação do graben de Pimenta Bueno, com preenchimento de arcóseos, conglomerados e folhelhos, ainda no Pré- Cambriano Superior.

\section{GRUPO BENEFICENTE}

Almeida e Nogueira Filho (1959) durante o reconhecimento do rio Aripuană denominaram de Grupo Beneficente à sequência constituída por uma litofácies inferior, de natureza psamítica e outra mais elevada, heterogênea de constituição predominantemente pelítica. A sequência tem como seção tipo, o rio Aripuana, em afloramentos isolados, cerca de $10 \mathrm{~km}$ à montante de Natal, nas vizinhanças da Fazenda do Igarapé Conceição, até $2 \mathrm{~km}$ acima do povoado de Beneficente. Aqueles autores admitem que tais rochas foram submetidas a um metamorfismo de baixo grau, que as transformou em quartzitos e ardósias.

Liberatore et alii (1972), na área do Projeto Aripuana - Sucunduri, apresentam três áreas de distribuiçăo da referida unidade. A primeira, abrangendo o médio curso dos rios Aripuanã. Juma e Branco; a segunda, no alto rio Sucunduri e a terceira, no baixo curso do rio Roosevelt. Estes autores admitem como metamórficas as rochas do Grupo Beneficente e consideram uma idade bem mais antiga que paleozóica inferior sugerida por Almeida e Nogueira Filho (op. cit.). Silva et alii (1974) nomearam de "Faixa Orogênica Aripuană - Teles Pires" às feições topográficas das serras do Cachimbo e A piacás.

Entre outros autores que se referem a esta unidade litoestratigráfica ressaltam-se Amaral (1974), Santos et alil (1975), Leal et alii (1978), Araújo et alii (no prelo).

O Grupo Beneficente, distribui-se principalmente nas porções norte, nordeste e centro norte da Folha SC.21 Juruena, formando uma faixa de aproximadamente $150 \mathrm{~km}$ de extensão, adentrando nas Folhas SB.20 Purus e SB.21 Tapajós. Esta faixa tem direçåo aproximadamente ONO-ESE, começando na parte oriental da Folha SC.21 Juruena na Chapada do Cachimbo, seguindo em direção ao rio Aripuană, formando em toda extensão um chapadăo.

O Grupo Beneficente repousa em discordância erosiva e paralela sobre o Grupo Uatuma. Nas inúmeras seçōes realizadas nos contatos entre as duas unidades litoestratigráficas, constatou-se a presença de conglomerado basal com seixos e calhaus de vulcânicas e granitos do Grupo Uatuma e/ou arenitos finos, ortoquartzíticos bem selecionados a arredondados. Na rodovia Cuiabá-Santarém, tanto a sul como a norte de Cachimbo, o contato é tectônico e faz-se com riolitos do Grupo Uatumå que estão sotopostos aos arenitos do Grupo Beneficente e bordejam o Graben do Cachimbo. Apesar das inúmeras citaçð̃es a respeito de intercalaçð̃es entre vulcânicas e os sedimentos do Grupo Beneficente năo se constatou nos inúmeros perfis realizados tal relação estratigráfica e acredita-se que essas intercalaçōes estejam condicionadas a áreas restritas.

Tassinari et alii (1978) apresentaram duas determinações $\mathrm{Rb} / \mathrm{Sr}$ para os sedimentos do Grupo Beneficente, com valores em torno de 1.400 m.a. Por outro lado, a idade relativa $e$ baseada na discordância estratigrafica entre o Grupo Beneficente e o vulcano-plutonismo (Grupo Uatuma) com isócrona $\mathrm{Rb} / \mathrm{Sr}$ de $1.589 \pm 36 \mathrm{~m}$.a.e a razão inicial $87 \mathrm{Sr} / 86 \mathrm{Sr}=0.7044$

0.0008 , enquanto que a parte sub-vulcânica, apresenta isócrona $\mathrm{Rb} / \mathrm{Sr}$ de $1.548 \pm 28 \mathrm{~m}$.a., com razăo inicial $87 \mathrm{Sr} / 86 \mathrm{Sr}=$ $0.707 \pm 0.001$.

No Domo do Sucunduri, rochas intrusivas nos sedimentos e vulcânicas apresentam valores convencionais $\mathrm{Rb} / \mathrm{Sr}$ de 1.394 $40 \mathrm{~m}$.a. (sienito) e $1.160 \mathrm{~m}$.a. (fonolito) (G.H. Silva et alit, no prelo).

Esta unidade litoestratigráfica apresenta uma variedade de litotipos, sendo mais abundantes os arenitos ortoquartzíticos, arcóseos, siltitos, folhelhos, calcários, chert, estromatólitos, raras ocorrências de fosfatos e arenitos glauconíticos, quartzitos e quartzo-mica xistos, restritos a zonas de falha.

Os arenitos mostram cores variegadas, tais como, cinza, rósea-avermelhada e predominantemente branca; granulaçăo que varia de fina a grossa, sendo as fraçoes fina a média predominantes. Apresentam-se acamadados com estratificação cruzada e plano-paralela. Os litotipos da base são bem seleci- 
onados, com os grãos arredondados, compostos essencialmente de quartzo, com crescimento autigênico. Graős de chert ocorrem em quantidade menos subordinadas que o feldspato. O cimento é tanto silicoso como ferrugioso.

Os sedimentos fosfáticos, cuja principal ocorrência é na Folha SB.20-Z-D, ao longo da rodovia BR-230 (Transamazônica), foram revelados por Araújo, Montalvão e Rodarte (1976), quando do reconhecimento da mesma. A exposição apresenta-se como um arenito esverdeado, com desenvolvimento de vegetação diferente no domínio da ocorrência. Em lâmina delgada ocorrem vários grãos de quartzo, pellets fosfáticos intercalados e presentes como varietais na rocha.

Chert e calcedonito são rochas que apresentam textura amigdalóide, esferulítica com cavidades. As amígdalas são preenchidas por calcedônia fibrosa. Entre as amígdalas observa-se esferulitos certamente quartzosos e grãos de quartzo.

Os arcóseos são constituídos de quartzo, chert, plagioclásio, microclina e ortoclásio. Os feldspatos estão alterados parcialmente a sericita e argilo-minerais.

Os calcários apresentam cor cinza, granulação areia fina a silte, estratificação plano-paralela, compostos quase que essencialmente de carbonato e raros grãos de quartzo. Observam-se também sericita, argilo-minerais, chert, zircão e opa$\cos$.

Nas zonas de falha e de dobramentos fechados, ocorrem de modo restrito, quartzitos e quartzo-mica xistos.

Os quartzitos têm textura granoblástica, grãos recristalizados, com arranjo poligonal. O quartzo é o principal constituinte, sendo que em outras amostras é secundado pela muscovita.

Os xistos são rochas de textura granolepidoblástica, compostos essencialmente de quartzo e mica. O quartzo exibe recristalização poligonal, com arranjo em mosaico, extinção ondulante. As palhetas de mica estão orientadas e formam a xistosidade da rocha.

\section{FORMAÇÃO MUTUM-PARANÁ}

Lobato et alii (1966) denominaram de Formação Mutum-Paraná os quartzitos e filitos que ocorrem na região de São Lourenço, Limeira e Abunã. Amaral (1974) aceita a correlação das formações Mutum-Paraná, Palmeiral e Parecis como proposta por Verschure e Bon (1972), acreditando que as mesmas representem diferentes fácies sedimentares e metamórficas de uma mesma unidade litoestratigráfica. Souza e alii (1975) admitem natureza vulcano-sedimentar em função dos tufitos intercalados na seqüência quartzito-filito. Leal ê alii (1978) englobam a Formação Mutum-Paraná no Grupo Beneficente.

A principal área de ocorrência da Formação Mutum-Paraná está a noroeste da Folha SC.20 Porto Velho, onde foi definida a unidade. Pinto Filho et alii (1976) correlacionaram os sedimentos situados nas Folhas SC.20-Z-A e SC.20-Z-C denominadas de Presidente Hermes e Pimenta Bueno. Leal et alii (op. cit.) posicionaram os sedimentos situados a sudeste da Folha SC.20 Porto Velho no Grupo Beneficente. Silva et alii (no prelo) admitem os sedimentos que ocorrem na borda a sudoeste da Folha SC. 21 Juruena, como correlacionáveis ao Grupo Beneficente.

Pinto Filho et alii (1976) fazem a correlação desta unidade litoestratigráfica com o Grupo Beneficente (Almeida e Nogueira Filho, 1959), assim como Leal et alii (op. cit) a correlacionam da mesma maneira. Pelo modo de exposição acredita-se que o Grupo Beneficente e a Formação Mutum-Paraná sejam provavelmente isócronos ou esta mais antiga, entretanto não se correlacionou como unidade litoestratigráfica devido as diferenças litológicas entre as mesmas. Estratigraficamente, está sobreposta aos polimetamorfitos do Complexo Xingu e vulcanitos do Grupo Uatumã, e sotopostos à Formação Dardanelos.

Verschure e Bon (op.cit.) apresentam idade em torno de 1250 m.a. para a Formação Mutum-Paraná. Pinto Filho et alii (op. cit.) a situam entre o magmatismo Uatumã, (1850 m.a. 1350 m.a.) e o evento ígneo Rondoniense.

Neste trabalho acredita-se que a Formação Mutum-Paraná apresente provável correlação cronoestratigráfica com o Grupo Beneficente ou é mais antiga que este.

Baseado nos dados de Pinto Filho et alii (op. cit.) e Leal et. alii (op. cit.), procurou-se citar as variedades litológicas sem a preocupação de uma descrição petrográfica mais detalhada. Para Pinto Filho et alii (op. cit.) a seqüência vulcano-clástica, com grande variação vertical, é constituída de metarenitos feldspáticos, metarcóseos, conglomerados, grauvacas, arcóseos, rochas xistosas, filonitos, quartzitos e piroclastos com maior expressão no Morro da Telerom, e ocorrências de ferro e manganês.ç

O metamorfismo imposto a esta unidade é dinamo-cataclástico, nas proximidades das zonas de falha devido a movimentação vertical de blocos e talvez um metamorfismo epizonal (?).

\section{GRUPO CAIABIS}

Lima et alii (1975) individualizaram e denominaram informalmente de unidade Pré-Cambriano II, a um espesso pacote vulcano-sedimentar, que se distribui por toda a parte central do Projeto A piacás-Caiabis. Baseados em fotointerpretaçĩo esses autores dividiram em subunidades Pré-Cambriano III. Pré-Cambriano II2 e Pré-Cambriano II3. Almeida e Nogueira Filho (1959) denominaram Formação Dardanelos aos dos, associados a ignimbritos, descritos na Cachoeira de Dardanelos, no rio Aripuanã e consideraram de idade provavelmente paleozóica antiga. Liberatore et alii (1972) notaram a existência de platôs baixos, situados principalmente no interflúvio Juma-Sucunduri e denominaram de "seqüência vulcano-sedimentar". Silva et alii (1974) citam essa formação como constituída de conglomerados e arenitos arcoseanos repousando discordantemente sobre os riolitos da Formação Iriri e chamaram-na Formação Prosperança. Silva et alii (no prelo) denominaram de Grupo Caiabis a seqüência vulcano-sedimentar que assoma na Folha SC.21 Juruena, ocupando o graben homônimo, com orientação NW-SE, sustentando a serra dos Caiabis. Esses autores subdividiram o Grupo Caiabis em Formação Dardanelos (Almeidà e Nogueira Filho, op. cit.) para a parte sedimentar e Formação Arinos para os derrames basálticos.

Padilha et alii (1974) denominam de unidade PE2 as rochas que recobrem a unidade $\mathrm{P} \in 1^{\mathrm{e}}$ ocupam as calhas sinclinais e os topos menos erodidos da região entre os paralelos $11^{\circ} \mathrm{OO}$ ' e $11^{\circ} 15^{\prime}$ e meridianos $59^{\circ} 00^{\prime}$ e $60^{\circ} \mathrm{OO}$ 'W.Gr. Correlacionam à Formação Dardanelos. Entre outros que se referem a esta unidade litoestratigráfica deve-se ressaltar Amaral (1974), Almeida (1974), Basei (1977) e Leal et alii (1978).

Neste trabalho conserva-se a denominação de Formação Dardanelos, proposta por Almeida e Nogueira Filho (op. cit.) aos litotipos encontradas na chapada de Dardanelos, nas proximidades da seção tipo. Na serra dos Caiabis ocorrem intercalações de basalto nos sedimentos arcoseanos semelhantes aos que assomam em Dardanelos. Corpos de andesito e riolito provavelmente seccionam os sedimentos.

$\mathrm{O}$ Grupo Caiabis repousa discordantemente sobre os metamorfitos do Complexo Xingu, vulcanitos do Grupo Uatumã e sedimentos dobrados da Formação Mutum-Paraná na parte sudoeste da Folha SC.21 Juruena.

Datações $\mathrm{K} / \mathrm{Ar}$ dos basaltos que se intercalam nos sedimentos do Grupo Caiabis revelaram idades de $1416 \pm 14$ $\mathrm{m}$.a. para o derrame inferior a $1225 \pm 20 \mathrm{~m}$. a. para o derrame superior (G.H. Silva et alii, no prelo). 


\section{FORMAÇÃO PRAINHA}

Almeida e Nogueira Filho (1959) descreveram no povoado de Prainha, no leito do igarapé homônimo e nos barrancos do rio Aripuanã, exposições de sedimentos detríticos vermelhos aos quais propuseram a denominação de Formação Prainha. Nesses sedimentos predominam siltitos e arenitos argilosos de granulação fina, ocorrendo localmente camadas de arenitos grosseiros e conglomerados.

Entre os vários autores que se referiram à Formação Prainha, ressaltam-se Caputo, Rodrigues e Vasconcelos (1971) que a correlacionaram à Formaçăo Prosperança. Silva et alii (1974) que aceitam a correlaçåo destes, assim como Santos et alii (1974) e Leal et alii (1978).

Neste trabalho baseando-se em seções realizadas no rio Negro, BR-154 e na região de Prainha, em sua localidade e seção tipo, achou-se precipitada tal correlação e usou-se a denominação proposta por Almeida e Nogueira Filho (op. cit.).

A principal distribuição desta unidade litoestratigráfica está na Fòlha SB.20 Purus, no ramal que liga a BR-230 (Rodovia Transamazônica) ao povoado de Prainha. Nesta rodovia e na Folha SC.20 Porto Velho, ocorre ampla exposição desta sequência mapeada na Folha SC.21 Juruena por Silva et alii (no prelo) dos domínios do Domo de Sucunduri.

Santos et alii (1975) posicionaram esta unidade no PréCambriano Superior com a denominação de Formação Prosperança. Leal et alii (op. cit.) e Araújo et alii (no prelo) admitem a unidde como pré-cambriana superior a eó-paleozóica. A Formação Prainha é uma unidade de cobertura que transgride sobre o Complexo Xingu, Grupo Uatuma e Grupo Beneficente. E provável que a mesma seja equivalente a Formação Dardanélos do Grupo Caiabis.

Năo existem dados concretos sobre a idade da Formaça Prainha. Entretanto se for verdadeira a correlaça com o Grupo Caiabis, esta unidade litoestratigráfica apresenta idade entre $1400 \mathrm{~m} . \mathrm{a} .-1200 \mathrm{~m} . \mathrm{a}$.

A Formação Prainha é composta por um conjunto de sedi. mentos vermelhos, característicos de ambiente continental, onde predominam os arenitos arcoseanos, argilosos, líticos, intercalando argilitos e siltitos vermelhos, com boa estratificação cruzada. Ocasionalmente ocorrem conglomerados com seixos de vulcânicas. Os arenitos são finos, arcoseanos e raramente ortoquartzíticos, de coloração predominantemente vermelha e, às vezes, tons róseos e cremes. A matriz é argilosa com impregnação de óxido de ferro. Manchas em lentes e fornıs irregulares ocorrem devido a concentração de argila. Estruturas primárias, plano-paralelas e cruzadas, ripple marks e clay galls săo comuns nestas rochas.

\section{GRUPO GUAJARÁ-MIRIM}

Leal et alii (1978) qualificaram de Grupo Guajará-Mirim à sequência vulcano-sedimentar que preenche os "grabens" dos Pacaás Novos e Uopione.

Aqueles autores subdividiram o Grupo Guajará-Mirim nas formações Nova Floresta e Pacaás Novos.

A Formação Nova Floresta é composta de vulcânicas básicas que estão situadas nas faldas das serras, em região tropograficamente situada abaixo das capas de arenitos (Leal et alii, op. cit.). As rochas básicas da referida formação foram enquadradas como basaltos alcalinos de granulação fina $e$ afanítica aparecendo subordinadamente textura diabásica.

O Grupo Guajará-Mirim forma as serras dos Pacaás Novos, Mirante e Uopione nas partes sudoeste e sul da Folha SC. 20 Porto Velho.

Não se tem a relação estratigráfica do Grupo Guajará-Mi rim com as demais unidades litoestratigráficas de coberturas descritas anteriormente. Baseados em idades radiométricas, conclui-se que este grupo formou-se posteriormente ao Caiabis. Na Folha SC. 20 Porto Velho, o Grupo Guajará-Mirim está sobreposto às rochas do Complexo Xingu e possivelmen- te sotoposto à Formação Pimenta Bueno e Cobertura Cenozóica.

Datações radiométricas realizadas em sete amostras de Basalto Nova Floresta revelaram idades entre 1038 m.a. -967 m.a. (Leal et alii, 1978).

Petrograficamente o Grupo Guajará-Mirim é representado por basaltos, arcóseos, subarcóseos, arenitos e quartzitos.

Os basaltos apresentam coloração cinza-esverdeada e granulação finníssima com núcleos de clorita e epídoto. Ao microscópio várias amostras exibem textura intergranular. $\mathrm{O}$ plagioclásio em ripas está alterado a sericita, epídoto e carbonato. $U$ piroxênio intersticial é a pigeonita, marrom-rosada. Em algumas amostras o piroxênio está totalmente substituído por clorita, carbonato e tremolita/actinolita. Os minerais secundários são clorita, epídoto, tremolita/actinolita, esfeno, carbonato e óxido de ferro. As vesículas são preenchidas por clorita, epídoto e carbonato. Variações de granulação mais grosseira com características de diabásio e gabro ocorrem na unidade litoestratigráfica.

Os arcóseos são os principais tipos litológicos da Formação Pacaás Novos (Leal et alii, op. cit.). Esta rocha é de granula cão fina a muito grossa, grãos subarredondados a subangulosos. O quartzo é constituinte principal, está microfraturado e exibe extinção ondulante. $O$ feldspato, segundo principal componente, é representado por microclínio, ortoclásio e plagioclásio. A sericita ocorre em palhetas contornando os grãos ou substituindo os feldspatos. Biotita e muscovita têm ocorrência mais restrita, assim como titanita, zircåo e calcedônia. Os fragmentos de rocha e chert são constantes nas amostras. O cimento é argiloso e silicoso.

Subarcóseos são rochas bastante similares às anteriores com feldspato subordinado.

Metarcóseos diferem dos arcóseos já citados, por sua textura granoblástica e feições que indicam leve metamorfismo dinầmico (?).

Conglomerados constituem a fração detrítica mais grosseira, são constituídos fundamentalmente por seixos, às vezes calhaus, sendo observados fragmentos arredondados e até por vezes angulosos de quartzo leitoso, quartiztos e vulcânicas. A matriz é abundante e de natureza arcoseana.

Arenitos são menos abundantes e representados por ortoquartzíticos, coloração rosada, estratificados e granulação média a grossa. O quartzo é praticamente o único constituinte. A presenta extinção ondulante, está microfraturado, exibe crescimento autigênico e tem formas subarredondadas e arredondadas. Ocorrem também fragmentos de chert e feldspatos, sendo o cimento silicoso.

Os quartzitos são produtos de metamorfismo dinâmico e térmico (?) que atuaram nos arenitos ortoquartzíticos.

\section{FORMAC̃̃̃ PIMENTA BUENO}

Oliveira (1915) verificou forte semelhança entre as rochas de um local próximo a Pimenta Bueno e os filitos dos rios Comemoração, Barão de Melgaço e Francisco Bueno, acreditando que tais rochas faziam parte da mesma sequiência sedimentar epimetamórfica com prolongamento até o rio $\mathrm{Ji}$ Paraná, considerando-a pertencente à Série Cuiabá, de idade pré-devoniana. Dequech (1943) constatou a existência de conglomerados e folhelhos no rio Apidiá, discordando da comparação de Oliveira (op. cit.), mas englobando tais rochas na Formação Parecis deste mesmo autor. Lobato et alii (1966) incluíram os folhelhos verdes que se esfoliam em pequenas placas e ocorrem na estrada entre Pimenta Bueno e Vilhena, na Formaçåo Parecis de Oliveira (op. cit.). Pinto Filho et alii (1976) denominaram de Unidade Permo-Carbonífero I (PCI) os folhelhos, arenitos, arenitos calcífero e dolomitos, que ocorrem no rio Pimenta Bueno e BR-364, afir. 
mando estar esta unidade litoestratigráfica restrita a uma bacia intracratônica tipo graben, acreditando ainda serem tais rochas a base de uma sequência sedimentar paleozóica. No mesmo trabalho aqueles autores identificaram "tilitos" sobrepostos aos folhelhos e arenitos do PCI, que denominaram de Unidade Permo Carbonífero II (PCII). Leal et alii (1978) denominaram Formaçăo Pimenta Bueno aos paraconglomerados, folhelhos e arcóseos que se encontram restritos ao graben de Pimenta Bueno.

Esta unidade lioestratigráfica ocupa o graben homônimo orientado no sentido ESE-ONO com cerca de $220 \mathrm{~km}$ de extensâo por $40 \mathrm{~km}$ de largura, localizado no quadrante meridional da Folha SC.20 Porto Velho.

As características litológicas e estruturais desta formação levaram Leal et alii (op. cit.) a posicionála estratigraficamente acima da Formaçăo Prosperança, estando discordantemente recoberta pelo Arenito da Fazenda Casa Branca.

Pinto Filho et alii (op. cit.) atribuiram à Formaçăo Pimenta Bueno idade permocarbonífera baseados na palinologia de arenitos da Unidade Permo-Carbonífero.I. A matriz dos tilitos da Unidade Permo-Carbonífero II que foi submetida por aqueles autores a análises palinológicas evidenciaram uma assembléia vegetal de idade carbonífero-permiana coexistindo com restos de Amazonites cruzi. Sommer e Costa (1972) referemse a estes palinomorfos encontrados nos arenitos existentes nas proximidades da Mineração Igarapé Preto (Folha SC. 20 Porto Velho) cuja idade é de pré-cambriana superior a eo-paleozóica.

Acredita-se na provável edificação do graben de Pimenta Bueno, e sedimentação da formação homônima, durante o Pré-Cambriano Superior e/ou Paleozóico Inferior, por reativaça plataformal.

Das litologias da Formação Pimenta Bueno, os arcóseos foram os mais amostrados. Esta rocha é de coloraçăo marrom e muito raramente avermelhada, de granulação fina a média, uniforme, constituída por quartzo com crescimento autigênico, plagioclásios, microclínio e ortoclásio desde límpidos até sericitizados e argilizados. Os opacos são comuns, e em quantidades menores ocorrem gråos de zircăo, turmalina, granada, pirita, palhetas de muscovita, biotita, sericita e clorita. Os poucos fragmentos de rocha são de quartzito, xisto ardósia ou argilito. $\mathrm{O}$ cimento pode ser tanto argiloso como ferruginoso.

Somente uma amostra de paraconglomerado foi esludada ao microscópio, revelando ser constituída de grãos com tamanho areia fina a calhau, angulosos a subarredondados. Os fragmentos de rocha são abundantes e constituídos por arcón seo, grauvaca, riolito, traquito, protomilonito, quartzo-diorito, com os outros constituintes detríticos tais como quartzo, microclínio, plagioclásio, ortoclásio, biotita, apatita e granada, com matriz escassa de clorita e argilo-minerais. $O$ cimento é ferruginoso e carbonático.

\section{ESTRUTURAS E DOBRAMENTOS}

A movimentação de blocos da crosta é o principal responsável pela tectogênese que atuou na área. Os movimentos verticais diferenciais ou mesmo horizontais de blocos foram causadores das extrusðes e intrusões ígneas, formaçōes de estruturas tafrogênicas (horsts e grabens) com sedimentação de psetitos, psamitos, pelitos e carbonatos com desenvolvimento de estruturas de biohermas.

O movimento diferencial de blocos da crosta, inclui os movimentos de massas ígneas, associados à falhas anelares e lincares, e fluxo de material mais plástico entre material menos plástico.

Os resultados das tafrogenias que atuaram na área foram descritos nos mínimos detalhes por Silva et alii (no prelo), Leal ef alii (1978) e Araújo et alii (no prelo). Citam-se aqui as estruturas com maiores expressð̃es sobre as quais depositaram as coberturas ou afetaram as mesmas, tais como graben (aulacógeno) do Cachimbo, graben dos Caiabis, Domo do Sucunduri, Alto Estrutural Juruena - Teles Pires, Alto Estrutural Eugênia - Arinos, graben dos Pacaás Novos, graben do Uopione, graben de Pimenta Bueno, Alto Estrutural do Rio Novo e Alto Estrutural do Javari.

As coberturas de plataforma têm como principal estilo de dobramento o block folding causado por movimento diferencial de blocos e somam-se também as intrusões magmáticas e fluxos de materiais mais plásticos (folhelhos, calcários, etc.). Estes dobramentos Bronguleyev (1972) denominou de pistons e classificou como "rígido" (blocos e placas) e "mole" (intrusões, diapirismo, etc.). Tais dobramentos descontínuos estão representados por estruturas dos tipos braquianticlinais, domos, braquissinclinais, anticlinais e sinclinais amplos.

Estas dobras eståo bem representadas no Grupo-Beneficente, na Folha SC.21 Juruena, e foram descritas cuidadosamente por Silva et alii (op. cit.), como Domo de Sucunduri, Sinclinal do Bararati, etc. O Grupo Beneficente, como dito acima, é a unidade litoestratigráfica que apresenta maior número de dobras idiomórficas. Observa-se que no extremo sul do graben (aulacógeno) do Cachimbo, nas proximidades das falhas, as dobras tomam características lineares, com eixos paralelos, dimensões de aproximadamente $100 \mathrm{~km}$ de eixos maiores e com características de dobras de flexuras (?). Afastando-se destas, tende-se para um dobramento amplo e des. contínuo, chegando-se à posição horizontal e suborizontal das camadas. Das observações conclui-se que as dobras do Grupo Beneficiente, em geral, são de cobertura de plataforma, isto é, região semi-estabilizada ou mesmo estabilizada, com dobras descontínuas ou idiomórficas. Em algumas regiōes, ocorrem dobras tipo lineares (flexura ?), sendo portanto um estilo misto de dobramento.

A Formaçăo Mutum-Paraná apresenta um conjunto de pequenas dobras com eixos, paralelos a subparalelos, limitados por sistemas de falhas com direçoes ENE e E-O. Apesar do paralelismo dos eixos, acredita-se que sua formaça esteja relacionada a movimento vertical dos blocos entre as falhas. Observa-se também uma nítida discordância no padrão estrutural de dobramento desta unidade litoestratigráfica nas porçðes SE da Folha SC.20 Porto Velho, e SO da Folha SC. 21 Juruena, com as outras unidades litoestratigráficas, principalmente em relação ao Grupo Beneficente e Grupo Caiabis.

Os grupos Caiabis e Guajará Mirim, Formação Prainha e Formação Pimenta Bueno, em geral, apresentam suas camadas horizontais a suborizontais, com mergulhos, ds vezes, acentuados nas proximidades das falhas, com basculamentos locais de blocos, colocando as camadas em posiçðes ate mesmo subverticais.

\section{METAMORFISMO}

As rochas que constituem o Grupo Beneficente năo apresentam metarmorfismo de caráter regional. O metamorfismo é local, relacionado a efeitos dinâmicos, nas zonas de falha, e térmico nas proximidades do contanto com efusivas e ou intrusões ígneas. $\mathrm{O}$ mesmo acontece com os grupo Caiabis e Guajara-Mirim e as formações Prainha e Pimenta Bueno, sendo que estas quatro unidades litoestratigráficas apresentam menos intensidade de dobramento e metamorfismo dinâmico.

A Formação Mutum-Paraná revela maior intensidade de dobramento, sendo também marcante os efeitos dinâmicos formando filonitos, quartzito, metarcóseos, metassiltitos, milonitos e cataclasitos. Apesar do conhecimento petrográfico limitado dessa formaçào, é provável que metamorfismo de epizona possa ocorrer nessa unidade litoestratigráfica, sem entretanto ter sido submetida a uma orogênese. 


\section{AGRADECIMENTOS}

Fica aqui registrado o agradecimento a todos os colegas ção deste trabalho. Em especial ao colega Vital José Ribeiro que contribuíram de modo direto ou indireto para a realiza- Wanderley pela leitura e crítica do mesmo.

\section{BIBLIOGRAFIA}

ALMEDA, F.F.M. de - 1974 - Evolucão Tectônica do Craton do Guaporé comparada com a do Escudo Báltico. R. Bras. Geoci., São Paulo, 4(3): 191-204.

ALMEIDA, F.F.M. de e NOGUEIRA FILHO, J.V. - 1959 - Reconhecimen 1o Geológico do Rio Aripuanå. B. Div. Geol. Mineral., Rio de Janeiro, (199), 43p

AMARAL, G. - 1974 - Geologia pré-cambriana da região Amazônica. São Paulo, Universidades, Instituto de Geociências, 212p./Tese de Livre Docência.

ARAÜJO, H.J.T. de et alit - Geologia. In: Brasil. Departamento Nacional da Producão Mineral. Projeio RADAMBRASIL. Folha SB.20 - Purus. Rio de Janeiro, no prelo. (Levantamento de Recursos Naturais, 17).

ARAÚJO, H.J.T. de; MONTALVÄO, R.M.G de e RODARTE, J.B.M 1976 - Reconhecimento Geológico na BR-319/Poto Velho - Manaus/

Transamazônica/Humaitá - Rio Juma/. Belém, Projeto RADAMBRASIL 10p. Anexos. (Relatório In erno RADAMBRASIL, $149 \mathrm{G}$ )

BASEI, M.A.S. - Idade do vulcanismo ácido a intermediário na região amazônica. São Paulo, Universidade, Instituto de Geociências. 133p. (Dissertação de Mesirado).

BRONGULEYEV, V.V. - 1972 - Classification and formation of the folded siructures of platforms. Int.Geol, Rev, V. $16 n^{\circ} 9$.

CAPUTO, M.V.; RODRIGUES, R. e VASCONCELOS, D.N.N. de - 1971 Litoestratigrafia da bacia do rio Amazonas. Belém, Peirobrás, Renor. (Relatório Técnico Interno, 641.A).

DEOUECH, V. - 1943 - Comissão para o Estudo de Jazidas Auríferas do Urucumacuan; Relatório Final. Rio de Janeiro. DNPM/DFPM, 53p (Relatório do Arquivo Técnico da DGM, 765).

LEAL, J.W.L. et alii. - 1978 - Geologia. In: Brasil. Departamento Naciona da Produçăo Mineral. Projeto RADAMBRASIL. Folha SC.20 - Porto Velho, Rio de Janeiro. (Levantamento de Recursos Naturais, 16).

LIBERATORE, G. et alii. - 1972 - Projeto Aripuanä-Sucunduri; Relatório Final. Manaus. DNPM/CPRM, 8v. (Relatório do Arquivo Técnico da DGM, 2000).

LIMA, PF.C. et alii - 1975 - Projeto Apiacás-Caiabis. Reconhecimento
Geológico Relatório Final Integrado. DNPM/CPRM. Goiânia, v.1. (Relatório do Arquivo Técnico da DGM, 2499).

LOBATO, F.P.N.S. et alil. - 1967 - Pesquisa de Cassiterita no Território Federal de Rondônia; Relalório Final. B.Div. Fom. Prod. Mineral, Rio de Janeiro, (125), 209p.

OLIVEIRA, E.P. de - 1915-1918 - Geologia, 1. Estudos feitos sobre amostras de rochas colhidas no Sertão de Mato Grosso. 2. Monografia sobre gesso. (Geologia Econômica) ocorrências, exploraç̃es e usos, Rio de Janeiro, pp. Macedo, 59p. (Brasil. Comissåo de Linhas Telegraphicas Estratégicas de Matto Grosso ao Amazonas. Anexo 3. publ. 59).

PADILHA, A.V et alit. - 1979 - Projeto Centro-Oeste do Mato Grosso. Rela tório Final. Goiânia, DNPM/CPRM. (Relatório do Arquivo Técnico da DGM. 2220)

PINTO FILHO, F.P. et alii - 1976 - Projeto Sudeste de Rondônia. Relatório de Progresso, 02. Porto Velho. DNPM/CPRM. 26p. (Relatório do Arquivo Técnico da DGM, 2559).

SANTOS, D.B. dos et alii - 1974 - Esboço Geológico da Folha SB.21 Tapajós. In: Congresso Brasileiro de Geologia, 28 ${ }^{\circ}$, Porto Alegre. Porto Alegre, Sociedade Brasileira de Geologia, v.4, p.277-287.

SANTOS, D.B. dos et alii - 1975 - Geologia. In: Brasil. Departamento Nacional da Produção Mineral. Projeto RADAMBRASIL. Folha SB.21 Tapajós. Rio de Janeiro. (Levantamento de Recursos Naturais, 7).

SILVA, G.H. et alii - 1974 - Esboço Geológico de parte da Folha SC.21 Juruena. In: Congresso Brasileiro de Geologia, 28 ${ }^{\circ}$. Porto Alegre. Anais... Porto Alegre, Sociedade Brasileira de Geologia, v, 4, p, 309-320.

SILVA, G.H. et alif - Geologia. In: Brasil. Departamento Nacional da Produção Mineral. Projeto RADAMBRASIL. Folha SC. 21 Juruena. Rio de Janeiro, no prelo. (Levantamen to de Recursos Naturais, 19).

SOUZA, E.C. et alii - Projeto Noroeste de Rondônia; Relatório Final. S.L. DNPM/CPRM. v. 1 (Relatório do Arquivo Técnico da DGM, 2548).

VERSCHURE, R.H. e BON, E.A. - 1972 - Geology and geocronology of-1in bearing vulcano-plutonic complexes in Rondônia. (Western Brazil) reflections on the genesis of this type of magmatism. A.R.Z.W.O. Lab isolopean. Geol. Amsterdam, 1970: 177-198.

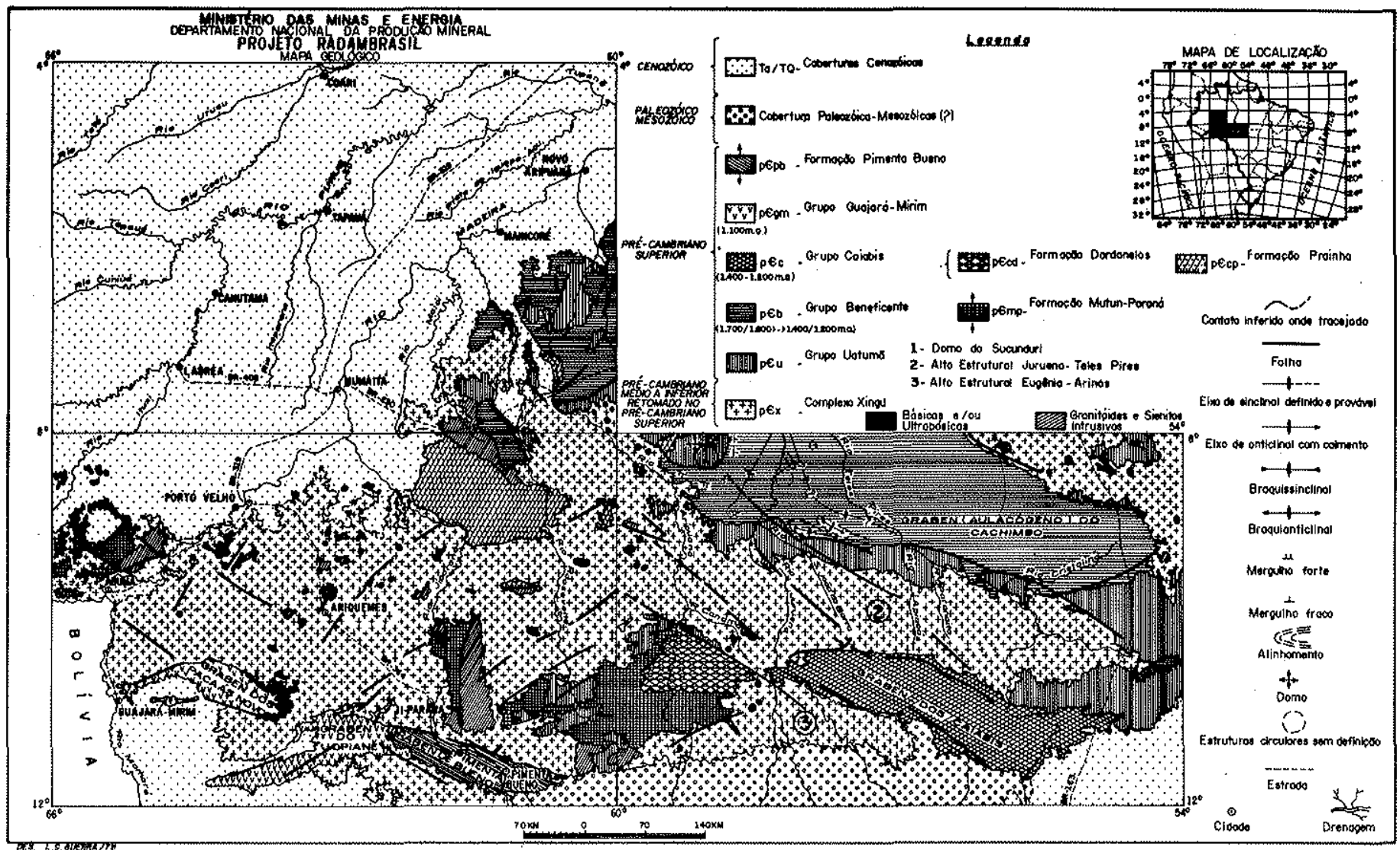

